\title{
Microtubule self-organisation during seed germination in Arabidopsis
}

\author{
Huifang Yan ${ }^{1,2,3}$, Nicole Chaumont ${ }^{1}$, Jean François Gilles ${ }^{4}$, Susanne Bolte ${ }^{4}$, Olivier Hamant ${ }^{5 \dagger}$ and \\ Christophe Bailly ${ }^{1 *+}$
}

\begin{abstract}
Background: Upon water uptake and release of seed dormancy, embryonic plant cells expand, while being mechanically constrained by the seed coat. Cortical microtubules (CMTs) are key players of cell elongation in plants: their anisotropic orientation channels the axis of cell elongation through the guidance of oriented deposition of load-bearing cellulose microfibrils in the cell wall. Interestingly, CMTs align with tensile stress, and consistently, they reorient upon compressive stress in growing hypocotyls. How CMTs first organise in germinating embryos is unknown, and their relation with mechanical stress has not been investigated at such an early developing stage.

Results: Here, we analysed CMT dynamics in dormant and non-dormant Arabidopsis seeds by microscopy of fluorescently tagged microtubule markers at different developmental time points and in response to abscisic acid and gibberellins. We found that CMTs first appear as very few thick bundles in dormant seeds. Consistently, analysis of available transcriptome and translatome datasets show that limiting amounts of tubulin and microtubule regulators initially hinder microtubule self-organisation. Seeds imbibed in the presence of gibberellic acid or abscisic acid displayed altered microtubule organisation and transcriptional regulation. Upon the release of dormancy, CMTs then self-organise into multiple parallel transverse arrays. Such behaviour matches the tensile stress patterns in such mechanically constrained embryos. This suggests that, as CMTs first self-organise, they also align with shape-derived tensile stress patterns.
\end{abstract}

Conclusions: Our results provide a scenario in which dormancy release in the embryo triggers microtubule selforganisation and alignment with tensile stress prior to germination and anisotropic growth.

Keywords: Arabidopsis thaliana, Cell elongation, Cortical microtubules, Dormancy, Germination, Seed

\section{Background}

From the onset of their development, all organisms express a network of molecular regulators which behaviour is constrained by the physical properties of their local environment and by the forces that cells generate [1]. Typically, in higher plants, growth starts with the expansion of an embryo within a seed which is constrained by

\footnotetext{
* Correspondence: christophe.bailly@sorbonne-universite.fr

${ }^{\dagger}$ Olivier Hamant and Christophe Bailly are senior authors who contributed equally to this manuscript.

'Laboratoire de Biologie du Développement, Sorbonne Université, CNRS, F-75005 Paris, France

Full list of author information is available at the end of the article
}

a stiff envelope [2]. Germination proceeds when dry seeds imbibe water and a growing radicle protrudes through the seed coat. Germination does not require cell division but is driven by elongation of cells of the embryonic axis [3, 4]. Water uptake, however, may not be sufficient to trigger germination. In particular, seed dormancy blocks their germination upon imbibition [5]. Dormancy is a transient phenomenon, dormant seeds being able to germinate only in a narrow range of environmental conditions. For example, dormant Arabidopsis thaliana seeds are usually unable to germinate above $20^{\circ} \mathrm{C}$ in darkness [6], but cold stratification releases dormancy within a few days. The mechanism of seed

(c) The Author(s). 2020 Open Access This article is licensed under a Creative Commons Attribution 4.0 International License, which permits use, sharing, adaptation, distribution and reproduction in any medium or format, as long as you give appropriate credit to the original author(s) and the source, provide a link to the Creative Commons licence, and indicate if changes were made. The images or other third party material in this article are included in the article's Creative Commons licence, unless indicated otherwise in a credit line to the material. If material is not included in the article's Creative Commons licence and your intended use is not permitted by statutory regulation or exceeds the permitted use, you will need to obtain permission directly from the copyright holder. To view a copy of this licence, visit http://creativecommons.org/licenses/by/4.0/ The Creative Commons Public Domain Dedication waiver (http://creativecommons.org/publicdomain/zero/1.0/) applies to the data made available in this article, unless otherwise stated in a credit line to the data. 
dormancy is far from being understood. It is under the antagonist crosstalk of two plant hormones, abscisic acid (ABA) and gibberellins (GAs). ABA maintains dormancy whereas GAs stimulate seed germination [5].

Osmolytes and reserves make dry seeds highly hyperosmotic, meaning that cell walls and plasma membrane are likely experiencing reduced tensile stress and tension, respectively. Data on fixed tissues also suggest that microtubules are often absent in dry seeds (e.g. in dry Jatropha curcas seeds [7]). Seeds are also one of the rare plant tissues where $\beta$-tubulin is even not detected by western blots in certain species (e.g. in dry tomato seeds [8]). Upon water entry, cells rapidly switch to a new osmotic status that pressurises the cells and increases tensile stress in cell walls and tension in membranes. At this time, the embryo is mechanically constrained by the seed coat for at least a day or two, until the radicle protrudes through the envelopes. Turgor-dependent tensile stress in cell walls has been shown to affect the microtubular cytoskeleton: cortical microtubules (CMTs) tend to align with the direction of maximal tensile stress [9, 10]. This response has been observed in many plant tissues [11], including the seed coat [12], and is classically thought to promote the deposition of cellulose microfibrils, and thus to reinforce the cell wall to resist tensile stress in a feedback loop. A recent report shows how CMTs change their orientation in artificially compressed hypocotyls: using a custom-built automated confocal micro-extensometer, CMTs become transverse upon longitudinal hypocotyl compression [13]. Interestingly, CMTs also change their orientation in response to ABA and GAs. For instance, GAs induce the formation of transverse CMTs in pea epicotyls, whereas ABA suppresses this effect $[14,15]$. This may involve key microtubule regulators, such as CLASP [16], SPIRAL1 and SPIRAL2 [17, 18], severing proteins such as KATANIN [19] and likely bundling proteins such as MAP65-1 and MAP65-2 [20].

The mechanical constraints applied by the seed coat on the imbibed embryo may therefore play a critical role in the dynamics of CMT organisation during seed germination. Surprisingly, this dynamics has never been described, and how the first CMT alignments appear during the transition from dry to germinating seed is not documented. In addition, whether regulation of seed germination by dormancy and hormonal balance may be related to CMT organisation and dynamics is not known. One indeed can wonder whether pressurisation of cells following water uptake has the same effect on cytoskeleton organisation in dormant and non-dormant seeds. The main objectives of this work were therefore to provide a description of CMT dynamics during the transition from dry to imbibed seeds and to determine whether it was regulated by dormancy. Transcriptome and translatome approaches were performed to determine whether microtubule self-organisation could be hindered by limiting amounts of tubulin and microtubule regulators. Studying CMT behaviour during germination was also a way to experimentally test predictions from [13] in a natural context. Based on our results, we propose a model in which dormancy release triggers CMT self-organisation and alignment with tensile stress during germination.

\section{Results \\ Upon imbibition, CMTs first appear as few bundles in random orientations in hypocotyls from dormant seeds}

As in the wild type, seeds from the $p 35 S:: G F P-M B D$ and p35S::GFP-TUB6 marker lines used in this study displayed dormancy: they were unable to germinate at $25^{\circ} \mathrm{C}$ in the darkness [6] (Additional file 1: Figure S1). Cold stratification progressively released seed dormancy of both lines (Additional file 1: Figure S1). Six hours of imbibition (HOI) was considered as an early time point where no elongation occurred. At $24 \mathrm{HOI}$, stratified seeds started to germinate (Additional file 1: Figure S1). In the following, we focus on the rootward region of the hypocotyl since most of the cell growth during Arabidopsis seed germination occurs in that region [3] (Additional file 2: Figure S2).

First, we analysed CMT behaviour using the p35S:: GFP-MBD line in dormant seeds (Fig. 1). After $48 \mathrm{HOI}$ of imbibition at $25^{\circ} \mathrm{C}$, no significant modification of hypocotyl cell morphology occurred in dormant seeds: cell length, width and surface did not change, consistent with the dormant status of these seeds (Fig. 1r, s). We quantified CMT orientation using the ImageJ macro FibrilTool [21]. Beyond average CMT orientation in each cell, this tool also provided a quantitative assessment of the anisotropy of the CMT arrays, where 0 means isotropic arrays and 1 means fully anisotropic arrays. Based on previous studies in hypocotyls, the measured anisotropy of CMT arrays rarely goes beyond 0.5 (see, e.g. [22]). At $6 \mathrm{HOI}$, a low number of microtubule bundles appeared, albeit without any clear orientation (Fig. 1a, h), in hypocotyl cells of dormant seeds. We found a low anisotropy of the CMT arrays (0.06, Fig. 1o) and rather isotropic CMT orientations $\left(54 \pm 28^{\circ}\right.$, Fig. 1p, q). Longer durations of imbibition did not markedly modify these parameters: after $48 \mathrm{HOI}$, the anisotropy of the CMT arrays was equal to 0.09 and CMT average angle equal to $44 \pm 25^{\circ}$ (Fig. 1c, j, o-q).

The microtubule-binding domain of the p35S::GFP$M B D$ line increases the rate of microtubule bundling, potentially leading to artefacts. To check whether the results obtained above are independent of the construct used to image the microtubules, we next conducted the same analysis using the $\beta$-tubulin marker line $p 35 S$ :: 
Non-dormant seeds

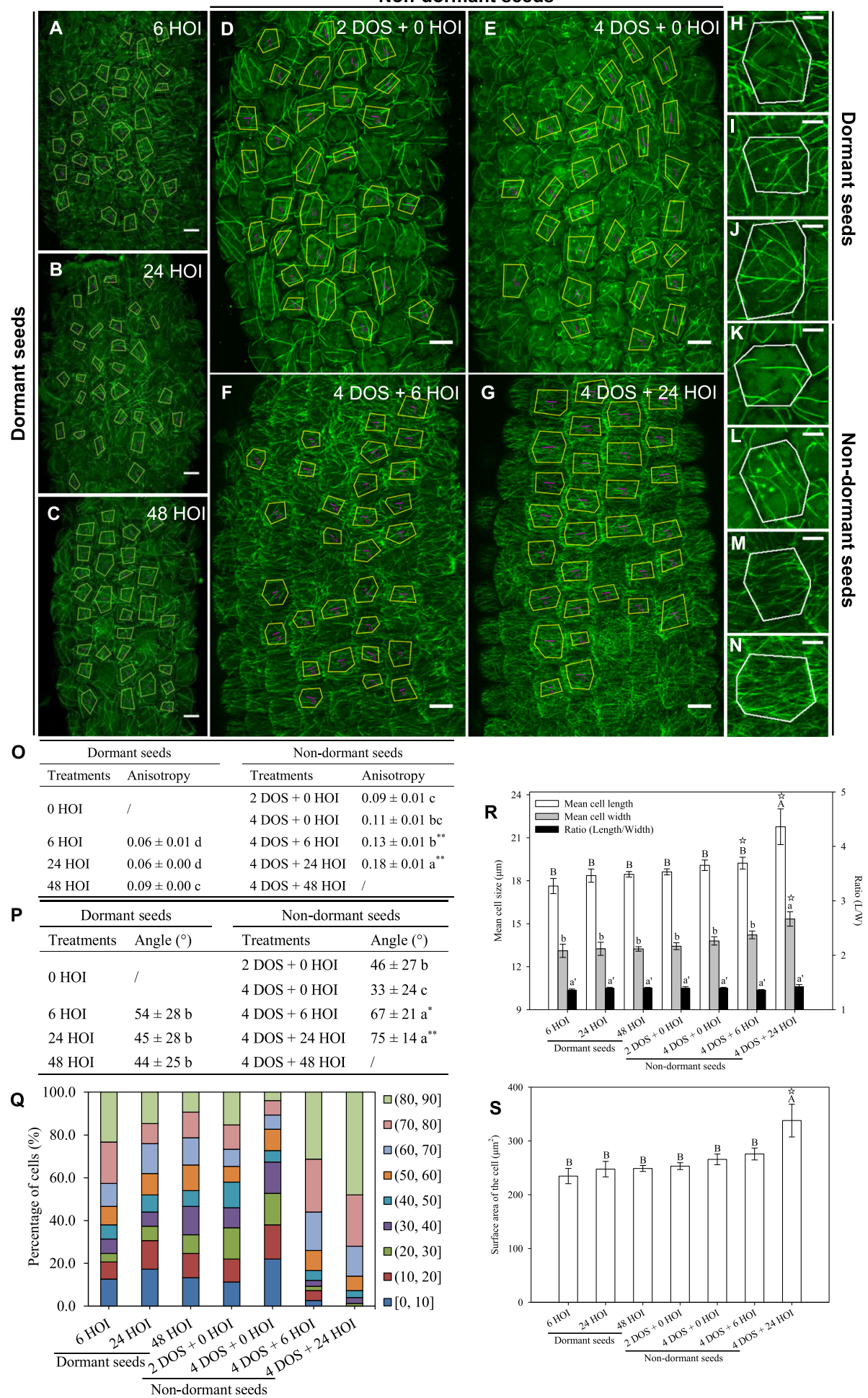

Fig. 1 (See legend on next page.) 
(See figure on previous page.)

Fig. 1 Microtubule organisation and hypocotyl cell shape in imbibed dormant and non-dormant p35S::GFP-MBD seeds. Microtubule average orientation (purple lines inside the cells) was obtained using FibrilTool in the regions of interest (cells excluding anticlinal walls) that are delineated with yellow lines (scale bars, $10 \mu \mathrm{m}$ ). Dormant seeds were imbibed at $25^{\circ} \mathrm{C}$ in the dark for 6,24 and $48 \mathrm{~h}$ (hours of imbibition ( $\mathrm{HOI}$ )) or stratified for 2 and 4 days (days of stratification (DOS)) then imbibed for 6 and $24 \mathrm{~h}$ at $25^{\circ} \mathrm{C}$ in the dark. Details of microtubule organisation are shown in individual cells of dormant embryos at 6,24 and $48 \mathrm{HOI}(\mathbf{h}, \mathbf{i}, \mathbf{j}$, respectively) and in cells of seeds after 2 DOS (k) and 4 DOS (I) followed by $6(\mathbf{m})$ and $24(\mathbf{n}) \mathrm{HOI}$. Values of anisotropy (o) and angles (p) were calculated for the same samples. In (o, $\mathbf{p})$ different letters indicated significant differences among all treatments (one-way ANOVA), and asterisks indicate significant difference between non-dormant seeds and dormant seeds at every the same time point ( $t$ test, ${ }^{*} P<0.05,{ }^{*} P<0.01$ ). q Angle distribution (expressed in \%) among cells is shown for every sample. Changes in cell shape were evaluated by measuring cell length and width $(\mathbf{r})$ and area $(\mathbf{s})$, in which different letters indicate significant differences among all samples (one-way ANOVA), and stars indicate significant difference between non-dormant seeds and dormant seeds at every the same time point ( $t$-test, $\left.{ }^{2} P<0.05\right)$. Values of CMT array angles $(\mathbf{p})$ are expressed as means \pm s.d., and values of CMT array anisotropy $(\mathbf{o})$ and cell shape $(\mathbf{r}, \mathbf{s})$ are expressed as means \pm s.e. (5 biological replicates were analysed, and 30 cells from each replicate were used to calculate the anisotropy, angles and cell shape)

GFP-TUB6. Overall, the analysis of CMT behaviour in the $p 35 S:: G F P-T U B 6$ line confirmed the findings obtained with $p 35 S:: G F P-M B D$ line (Fig. 2). Upon imbibition of dormant seeds at $25^{\circ} \mathrm{C}, p 35 S:: G F P$-TUB6 CMTs formed very few scattered bundles, with no dominant orientation (Fig. $2 \mathrm{a}-\mathrm{c}, \mathrm{h}-\mathrm{j}$ ), as demonstrated by the relatively constant and low values of CMT array anisotropy and high standard deviation for CMT angle values (65 \pm $19^{\circ}$ at $6 \mathrm{HOI}$ and $53 \pm 26^{\circ}$ at $24 \mathrm{HOI}$, Fig. $2 \mathrm{o}-\mathrm{q}$ ).

The presence of microtubule bundles could be explained by the sudden increase in mechanical stress, as water inflates the cells, as shown for instance when tissues are exposed to indentation (e.g. [23]) or after pharmacological wall weakening (e.g. [24]). Yet, at this stage, the low number of bundles suggests that the formation of CMTs is constrained by unknown factors.

\section{CMTs form close to transverse arrays in hypocotyls from germinating non-dormant seeds}

Next, we performed the same analysis upon cold $\left(4{ }^{\circ} \mathrm{C}\right)$ stratification for 2 and 4 days, to release dormancy, and after transfer in the dark at $25^{\circ} \mathrm{C}$ (Figs. $1 \mathrm{~d}-\mathrm{g}$ ). In the $p 35 S$ :: GFP-MBD background, the microtubule network features were not dramatically modified by 4 days of stratification (DOS): the anisotropy of the CMT array reached 0.11 , and CMT orientations were still isotropic with a mean angle of $33 \pm 24^{\circ}$ (Fig. 1d, e, k, l, o-q), while cell morphology remained unchanged (Fig. 1r, s). However, as seeds progressed towards germination during imbibition at $25^{\circ} \mathrm{C}$, cell morphology changed with a significant increase in length, width and surface area (Fig. 1r, s). At $4 \mathrm{DOS}$ and $24 \mathrm{HOI}$, the number of CMT arrays increased and the anisotropy of the CMT arrays reached 0.18 , reflecting their increased parallel alignments. CMTs also displayed consistent orientations between neighbouring cells: the standard deviation of the CMT angle was down to $14^{\circ}$ (Fig. $1 \mathrm{o}-\mathrm{q}$ ), and the mean angle of the CMT arrays was close to transverse, with a measured angle of $75^{\circ}$ (Fig. 1p). This behaviour is consistent with predictions from [13] in artificially compressed hypocotyls. Similar conclusions were obtained when using the p35S::GFP-TUB6 line (Fig. 2).

Altogether, these results demonstrate that germination is associated with an increase in the order of CMT arrays. In contrast, seed dormancy is associated with disorganised CMT arrays; water imbibition and cold treatment alone are not sufficient to trigger consistent CMT alignments.

\section{Germination is associated with stereotypical transcriptional and translational responses of microtubule-related genes}

Upon water entry, the hypocotyl becomes pressurised, meaning that the cylindrical shape of the tissue may prescribe a maximum of tensile stress in the transverse direction for these cells. We wondered why CMTs would be insensitive to such directional cues in hypocotyls from dormant seeds. The alignment of CMT arrays in uniform orientations involves self-organisation processes: the final orientation of CMT arrays is the result of their interactions through (de)polymerisation, bundling and severing [25-27]. Following changes in tensile stress direction, CMTs reorient through such selforganising processes. We therefore reasoned that dormancy might hinder the expression of key microtubule regulators, thereby hampering the ability of microtubules to respond to stress.

To test that hypothesis, we followed the changes in expression of key genes likely to be involved in microtubule organisation and synthesis by qRT-PCR in Col-0 seeds (Fig. 3). The expression level of $\alpha$ - and $\beta$-tubulin genes was low in dormant dry seeds and during their subsequent imbibition at $25^{\circ} \mathrm{C}$ whereas cold stratification progressively induced their upregulation (Fig. 3a-e). TUB6 expression, noticeably, was dramatically stimulated at $24 \mathrm{HOI}$ (Fig. 3e). The expression of TUBG1, coding for $\gamma$-tubulin, followed a similar trend but in a much lower extend (Fig. 3f). The expression of the two 


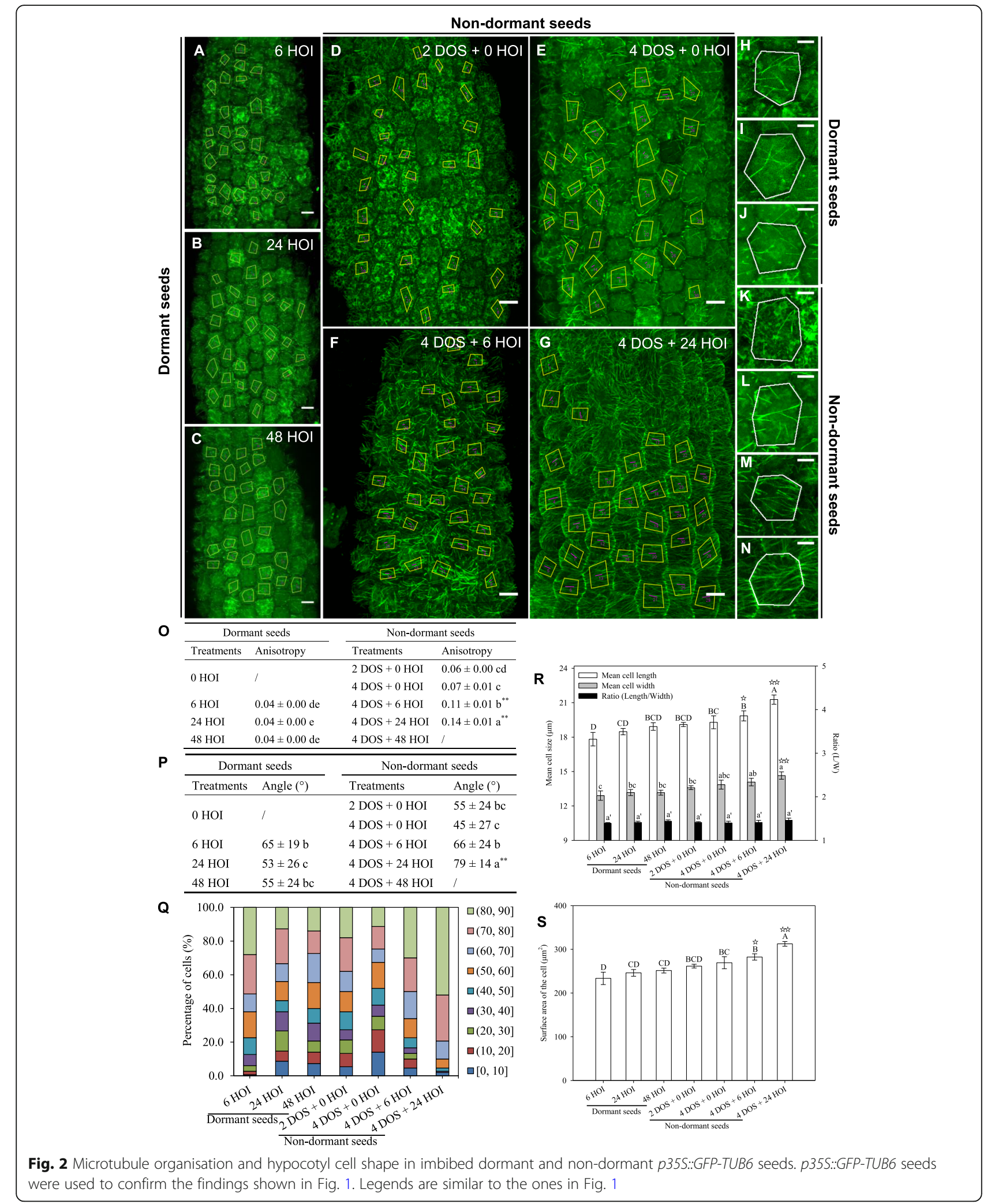

main microtubule-associated proteins involved in microtubule bundling, MAP65-1 and MAP65-2 [27], followed the same pattern as tubulin genes (Fig. 3g, h). Katanin
(KTN1) is a microtubule-severing protein which contributes to microtubule self-organisation and to embryo and seed formation in Arabidopsis [28]. Its expression 

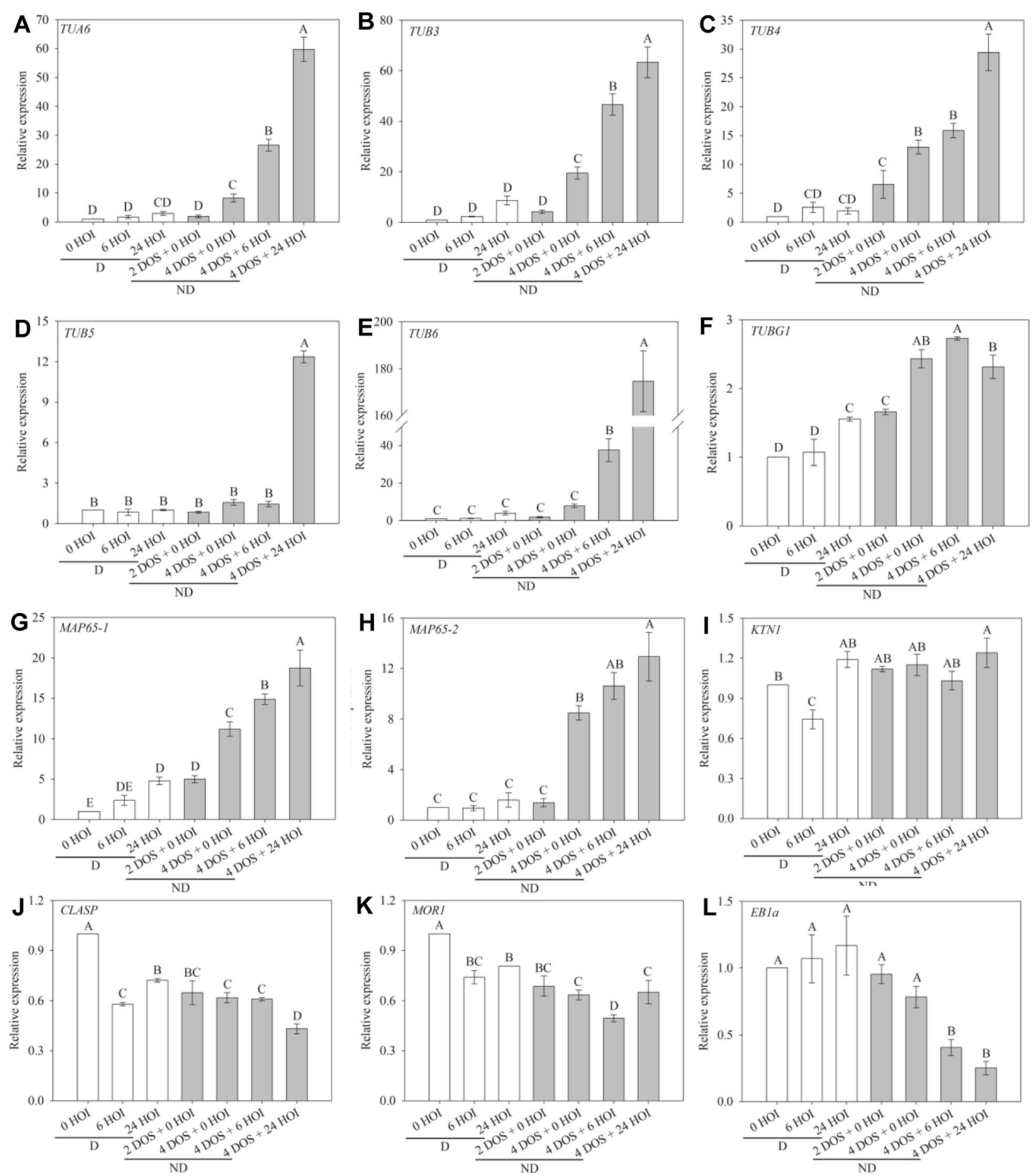

Fig. 3 Reorganisation of microtubules during germination is associated with changes in the expression of microtubule-related genes. Relative expression of TUA6 (a), TUB3 (b), TUB4 (c), TUB5 (d), TUB6 (e), MAP65-1 (f), MAP65-2 (g) and EB1a (h) genes in dormant and non-dormant Arabidopsis seeds. $\mathrm{HOI}$, hours of imbibition at $25^{\circ} \mathrm{C}$ in the dark; DOS, days of stratification at $4{ }^{\circ} \mathrm{C}$ in the dark. $0 \mathrm{HOI}$ corresponds to dry dormant seeds and is used as a reference condition. Different letters indicate significant differences among samples (one-way ANOVA). Values are the means \pm s.e. of 3 independent biological replicates with 3 technical replicates each

remained unchanged whatever the seed sample (Fig. 3i). CLASP encodes a microtubule-associated protein which promotes CMT self-organisation by stabilising their polymerisation at cell edges [29, 30]. MICROTUBULE ORGANIZATION 1 (MOR1) is a member of the highly conserved MAP215 family of microtubule-associated 
proteins that contribute to microtubule polymerisation $[31,32]$. The expression of both CLASP and MOR1 genes was lower in imbibed seeds than in dry seeds and was not affected by the dormancy status (Fig. 3j, k). End binding 1a $(E B 1 a)$ stabilises microtubule plus ends [33]. Its expression was high in dry and imbibed dormant seeds, but it decreased markedly during stratification and imbibition of non-dormant seeds (Fig. 3l). Altogether, this suggests that the release of dormancy by cold stratification induces progressive changes in microtubule behaviour during germination, notably through transcriptional induction of tubulin and bundling factors (like MAP65), while imbibition alone is not sufficient to trigger the expression of the complete set of microtubule regulators.

The presence of mRNA is only an indirect indication of gene function. To further check whether protein translation followed the same trend, we explored previously obtained data related to changes in translatome, i.e. transcripts associated with polysomes and undergoing active translation, in dormant and non-dormant seeds at 16 and $24 \mathrm{~h}$ of imbibition at $25^{\circ} \mathrm{C}$ (Additional file 3: Table S1) [34]. In dormant seeds, proteins involved in microtubules nucleation, such as $\gamma$-tubulin, were translated, but proteins involved in microtubule dynamics, such as tubulin (essential for microtubule polymerisation) or MAP65 (essential for microtubule bundling), were likely in limited number (Additional file 3: Table S1). Conversely, upon the release of dormancy, the corresponding mRNAs were translated, matching the formation of organised CMT arrays. CLASP, MOR1 and KTN1 mRNAs were not found in the translatome. Incidentally, the translatome also revealed major modifications in the profile of cell wall modifiers, including promoters of wall weakening, such as pectin lyases and expansins. We could also confirm the induction of tubulin $\alpha$ expression at the protein level by western blot (Additional file 4: Figure S3): $\alpha$-tubulin accumulated in stratified seeds only, prior to radicle protrusion.

Altogether, these results provide a scenario in which water imbibition changes the stress pattern before the CMTs are able to respond, because the microtubule dynamics protein network is not fully operational yet.

\section{Hormone-dependent modulation of dormancy regulates microtubule organisation}

If true, our hypothesis should be verified whether dormancy is released by cold or by other means. In particular, upon treatment with GA, which is also known to accumulate during cold stratification [35], seeds became able to fully germinate at $25^{\circ} \mathrm{C}$ within $4-5$ days, without any cold stratification treatment (Additional file 1: Figure $\mathrm{S} 1 \mathrm{c}$ ). When treated with $\mathrm{GA}_{3}$, the induction of germination could be detected by changes in cell shape and size (Fig. 4p, q). Microtubules progressively became more ordered in the $p 355:: G F P-M B D$ line, and this was associated with an increase in CMT array anisotropy (from 0.11 after $6 \mathrm{~h}$ of $\mathrm{GA}_{3}$ treatment to 0.18 after $48 \mathrm{~h}$ of $\mathrm{GA}_{3}$ treatment) and reduced standard deviation of CMT angles (from $60 \pm 23^{\circ}$ after $6 \mathrm{~h}$ of $\mathrm{GA}_{3}$ treatment to $81 \pm 8^{\circ}$ after $48 \mathrm{~h}$ of $\mathrm{GA}_{3}$ treatment) (Fig. $4 \mathrm{~m}-\mathrm{o}$ ). The impact of the release of dormancy on CMTs is thus not strictly dependent on cold, but rather seems a generic feature of the early steps of germination.

Conversely, germination can be inhibited by ABA. When using this treatment on stratified seeds (i.e. nondormant seeds), we observed that, during seed imbibition, cell length, width and surface area did not evolve significantly (Fig. 4p, q). Consistently, CMTs remain disorganised in the $p 35 S:: G F P-M B D$ line (Fig. $4 \mathrm{~g}-\mathrm{i}, \mathrm{j}-\mathrm{l}$ ). In fact, we could even detect a decrease of CMT array anisotropy (from 0.11 after $6 \mathrm{~h}$ of ABA treatment to 0.05 after $48 \mathrm{~h}$ of $\mathrm{ABA}$ treatment) when stratified seeds were imbibed in the presence of ABA (Fig. 4m). Accordingly, the standard deviation of CMT array angles remained high during seed imbibition $\left(49 \pm 25^{\circ}\right.$ at $6 \mathrm{~h}$ and $47 \pm 25^{\circ}$ at $48 \mathrm{~h}$ after ABA treatment, Fig. $4 \mathrm{n}, \mathrm{o}$ ). This confirms that imbibition is not sufficient to trigger a change of CMT behaviour and that dormancy needs to be released for CMT arrays to become more ordered.

\section{Expression of microtubule regulators during the release of dormancy is under hormonal control}

To further confirm our hypothesis, we also checked the expression of some genes involved in microtubule dynamics after the hormone treatments. TUA6, TUB5 and TUB6 gene expression increased in the presence of $\mathrm{GA}_{3}$, and this was not the case in the presence of ABA (Fig. 5a, $\mathrm{d}, \mathrm{e})$. Note that TUB3 and TUB4 gene expression tended to increase during seed imbibition either in the presence of $\mathrm{GA}_{3}$ or ABA (Fig. 5b, c). TUBG1 expression was slightly stimulated in the presence of either $\mathrm{ABA}$ or $\mathrm{GA}_{3}$ (Fig. 5f). The expression of MAP65-1 and MAP65-2 increased during imbibition of dormant seeds in the presence of $\mathrm{GA}_{3}$ (Fig. $5 \mathrm{~g}, \mathrm{~h}$ ), when it remained unchanged or decreased, respectively, in the case of non-dormant seeds imbibed with ABA (Fig. 5g, h). The expression of KTN1 remained unchanged whatever the seed treatment (Fig. 5i). $\mathrm{GA}_{3}$ treatment induced a downregulation of CLASP, MOR1 and EB1a, after $48 \mathrm{~h}$ of imbibition of dormant seeds (Fig. 5j-1). In the presence of ABA, CLASP, MOR1 and EB1a expression also started to decrease after 6 and $24 \mathrm{~h}$ of imbibition but abruptly increased at $48 \mathrm{~h}$ (Fig. $5 \mathrm{j}-\mathrm{l}$ ). However, the amplitude of variation of expression of these 3 genes was very weak (always lower to 2-fold). The role of the hormonal balance on CMT organisation was confirmed by studying the expression of the same genes during germination of mutants altered 

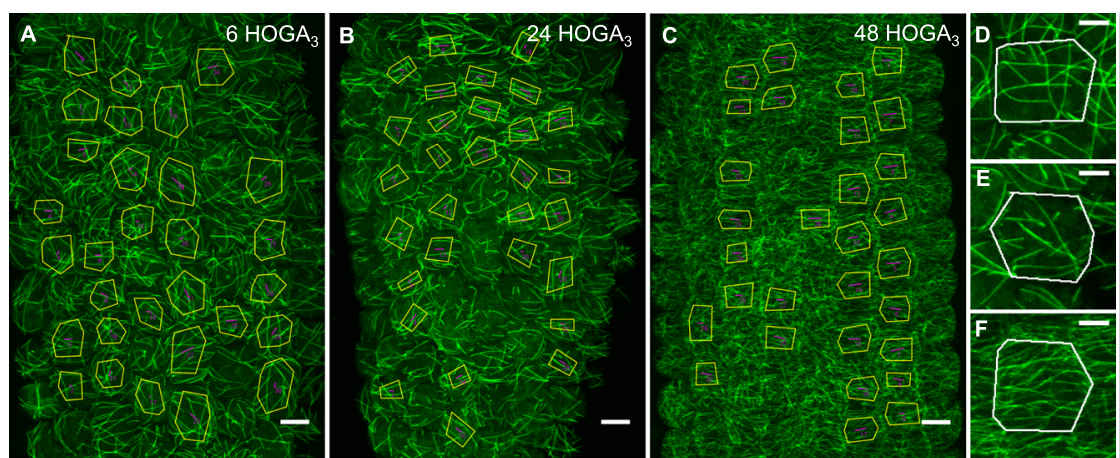

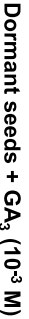
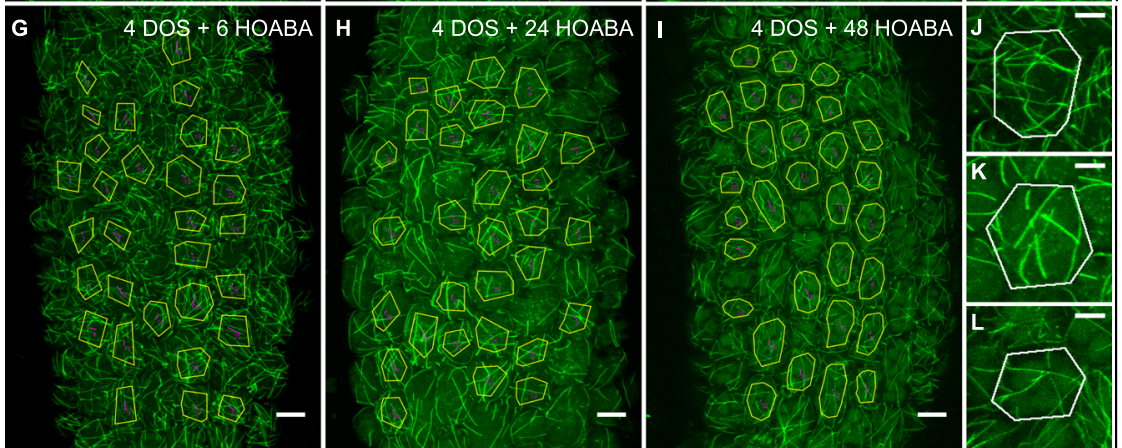

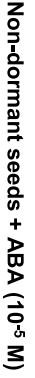
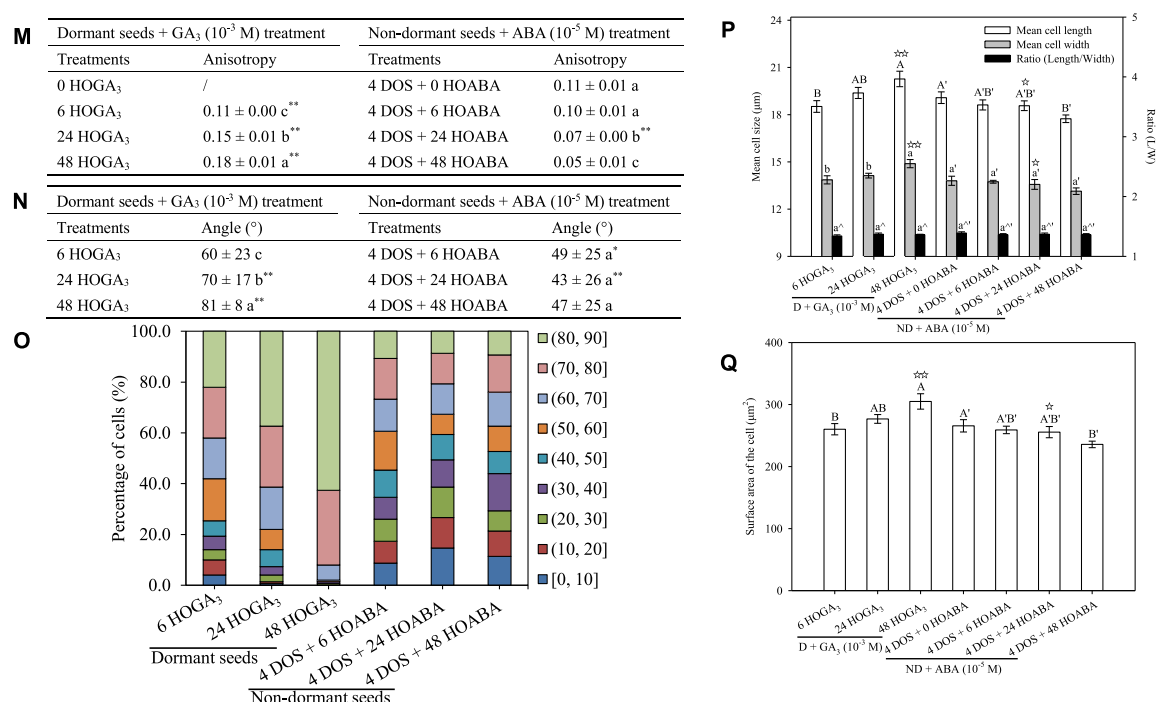

Fig. 4 Gibberellic acid and abscisic acid modify microtubule organisation in dormant and non-dormant seeds. Microtubule organisation was assessed in embryos of dormant and non-dormant (4 days of stratification (DOS)) p35S::GFP-MBD seeds imbibed for 6, 24 and $48 \mathrm{~h}$ (HOI) in the presence of gibberellic acid $\left(G_{3}, 1 \mathrm{mM}\right)(\mathbf{a}-\mathbf{f})$ and abscisic acid $(A B A, 10 \mu \mathrm{M})(\mathbf{g}-\mathbf{I})$, respectively. Microtubule average orientation (indicated by purple lines inside the cells) was obtained using FibrilTool and is shown in the regions of interest (cells excluding anticlinal walls) that are delineated with yellow lines (a-c and $\mathbf{g}-\mathbf{i}$ ). $\mathbf{d}-\mathbf{f}$, $\mathbf{j}-\mathbf{I}$ Microtubule organisation at the level of individual cells from dormant seeds imbibed for 6,24 and $48 \mathrm{~h}$ with $\mathrm{GA}_{3}$ and from non-dormant seeds imbibed for the same duration with ABA, respectively (scale bars, $10 \mu \mathrm{m}$ in images of multicellular hypocotyl and $5 \mu \mathrm{m}$ in images of individual cells). Values of anisotropy (m) and angles (n) of CMT arrays were calculated for the same samples. In ( $\mathbf{m}, \mathbf{n})$ different letters indicated significant differences within the same column (one-way ANOVA), and asterisks indicate significant difference between non-dormant seeds and dormant seeds at every the same time point ( $t$ test, $\left.{ }^{*} P<0.05,{ }^{* *} P<0.01\right)$. o Angle distribution (expressed in \%) among cells of the various samples is shown for every sample. Changes in cell shape were evaluated by measuring the cell length and width $(\mathbf{p})$ and area $(\mathbf{q})$, in which different letters indicate significant differences among all samples of GA $\mathrm{A}_{3}$ or $\mathrm{ABA}$ treatments (one-way ANOVA), and stars indicate significant difference between non-dormant seeds and dormant seeds at every the same time point ( $t$ test, is $P<0.05$, 衫 $P<0.01)$. Values of CMT array angles $(\mathbf{n})$ were expressed as means \pm s.d. while values of CMT array anisotropy $(\mathbf{m})$ and cell shape $(\mathbf{p}$. q) were expressed as means \pm s.e. Five biological replicates were analysed, and 30 cells from each replicate were used to calculate the indicated values 

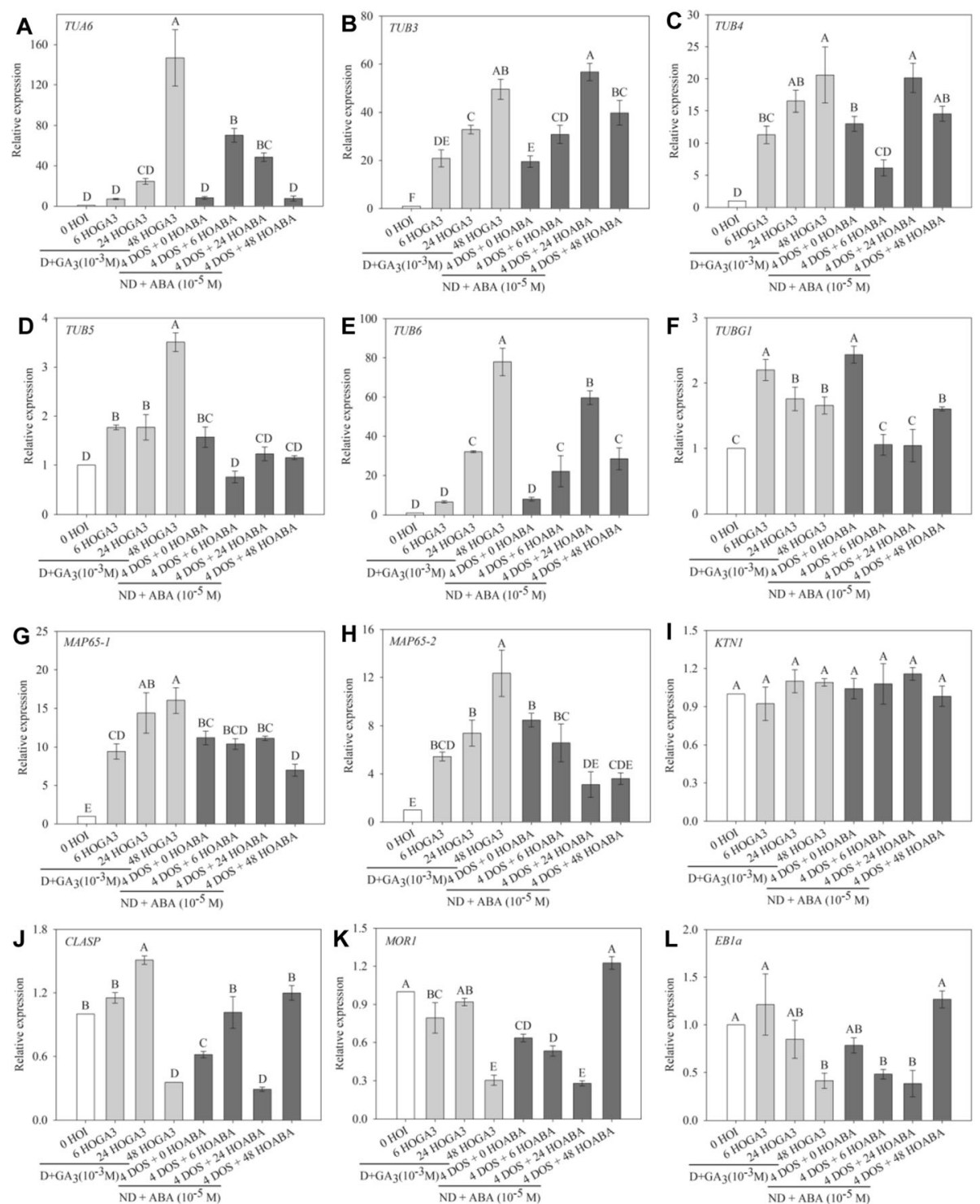

Fig. 5 Transcriptional regulation of microtubule organisation by $\mathrm{GA}_{3}$ and ABA. Relative expression of TUA6 (a), TUB3 (b), TUB4 (c), TUB5 (d), TUB6 (e), MAP65-1 (f), MAP65-2 (g) and EB1a (h) genes in dormant and non-dormant Arabidopsis seeds. HOl, hours of imbibition at $25^{\circ} \mathrm{C}$ in the dark; DOS, days of stratification at $4{ }^{\circ} \mathrm{C}$ in the dark. $0 \mathrm{HOl}$ corresponds to dry dormant seeds and is used as a reference condition. Dormant seeds (d) were imbibed at $25^{\circ} \mathrm{C}$ in the presence of gibberellic acid $\left(\mathrm{GA}_{3}\right)$ for 6,24 and $48 \mathrm{~h}\left(6 \mathrm{HOGA}_{3}, 24 \mathrm{HOGA}_{3}\right.$ and $48 \mathrm{HOGA}_{3}$, respectively). Stratified non-dormant seeds (ND) were imbibed at $25^{\circ} \mathrm{C}$ on water (0 HOABA) and in the presence of abscisic acid (ABA) for 6,24 and $48 \mathrm{~h}(6 \mathrm{HOABA}, 24$ $\mathrm{HOABA}$ and $48 \mathrm{HOABA}$, respectively). Different letters indicate significant differences among samples (one-way ANOVA). Values are the means \pm s.e. of 3 independent biological replicates with 3 technical replicates each

in GA or ABA signalling, using publicly available transcriptomic data (Additional file 5: Figure S4). In ABA signalling mutants, and particularly in abi3-4, abi4-11 and abi5-7, genes involved in microtubule organisation and synthesis were overexpressed during seed imbibition, excepted for TUA6, KTN1 and MOR1. In the seeds of the GA-deficient mutant ga1-3, only TUA6 and MAP65-2 were downregulated, whereas the expression of the other genes did not vary. There were no data available concerning the expression of EB1a in mutant seeds.

\section{Discussion}

The role of biomechanics in seed germination is attracting increasing attention $[2,36]$, notably to reveal the role of endosperm weakening as a regulator of radicle protrusion [36]. Here, we report the organisation of CMTs as they appear during seed imbibition and germination, and we demonstrate that the release of dormancy triggers their self-organisation into parallel arrays. We show that the dynamics of CMT leading to their transverse orientation in the hypocotyl area of the embryonic axis, 
i.e. where cell expansion takes place [3, 4], is tightly associated with radicle protrusion and is regulated by the dormancy status. To observe CMT, we had to remove the seed coat. Such perturbation may induce artefactual CMT behaviour. Based on the data obtained in shoot apical meristems and cotyledons, it appears that CMT can retrieve a normal behaviour within 6 to $16 \mathrm{~h}[23,37]$. Although we cannot formally exclude a contribution of this initial perturbation, our observations were conducted for several days, and thus, it is unlikely that the observed CMT behaviour in the long term is caused by this initial perturbation. Furthermore, the comparison of CMT behaviour between dormant and non-dormant seeds offers an internal control for the effect of seed coat removal on CMT organisation. We indeed observed that bundling disappears upon the release of dormancy and remains unchanged when dormancy is maintained, which offers an intrinsic control to make sure that the degree of MT bundling is not only the result of seed coat removal. The ability of seeds to germinate relies on a rapid reorganisation of CMTs, initiated as early as $6 \mathrm{~h}$ of imbibition (Figs. 1, 2 and 5). This process is not strictly related to the changes in turgor pressure occurring when a dry quiescent seed gets imbibed: 4 days of stratification or imbibition of dormant seeds did not markedly modify CMT organisation. This finding was confirmed by using ABA, which blocked germination, and $\mathrm{GA}_{3}$, which alleviated dormancy: both hormones had antagonistic effects on CMT organisation (see Fig. 5). Beyond tensile stress, the effect of the plant hormones $\mathrm{ABA}$ and GAs on microtubule organisation has already been demonstrated but often in other contexts than germination [14, 38, 39]. In these reports, ABA treatment usually results in a predominance of longitudinal CMTs, whereas GAs induce predominance of transverse CMTs. Da Silva et al. [40] reported that exogenous ABA could inhibit transverse organisation of CMT in imbibed coffee seeds. CMT reorganisation in imbibed seeds would therefore require a state of competence controlled by both exogenous (i.e. appropriate temperature) and endogenous (i.e. dormancy status and hormones) factors, allowing CMTs to form multiple arrays. As they become able to self-organise, CMTs also become sensitive to tensile stress, and their consistent transverse orientation then fuels subsequent directional cell elongation (Fig. 6).

Using an automated confocal micro-extensometer, CMTs were shown to become transverse in compressed hypocotyls [13]. Our results are consistent with these findings, albeit in the natural context of an expanding embryo where the constraint is brought by the stiff envelope of the seed and the endosperm layer and not by a micro-extensometer. We cannot exclude that other factors than mechanical stress only could explain the transverse orientation of CMTs in germinating embryos. For instance, cell shape is a well-known factor that biases CMT orientation. In particular, because of their intrinsic stiffness, CMTs may align so as to minimise their bending energy, and thus preferentially align along the flattest part of the cell. This steric constraint has been proposed to explain why microtubules can align with the longitudinal axis of the cells in silico [41], in confined cells $[42,43]$ and in tissues undergoing growth arrest [44]. Conversely, microtubule regulators, such as CLASP, have been proposed to help microtubule bend at cell edges [30]. In the germinating embryos, changes in cell shape are minimal, cell shapes are rather isotropic and adjacent cells do not have consistent shapes. Therefore, cell shape alone cannot explain the consistent alignment of CMTs in hypocotyl cells. Hormone gradients could also provide a directional cue that could explain the consistent alignment of CMTs. Such gradients have been shown recently to play a critical role in the completion of germination [45]. However, we observed that CMTs became transverse over the whole length of the hypocotyl, i.e. without a clear gradient, which is consistent with a response to an instantaneous and global compression event. We propose that the impact of hormones on CMTs might rather be indirect, through the expression of microtubule regulators, giving them the competence to self-organise, and through their impact on cell wall properties and/or turgor pressure, to affect mechanical stress levels. As long as the seed envelope remains intact, embryo cells would be mechanically protected despite their turgor pressure building up, whereas upon seed envelope breakdown, aligned CMTs would be required to reinforce cell walls through cellulose synthesis.

Gene expression analysis allowed us to show a transcriptional regulation of CMT reorganisation during germination (see Figs. 3 and 6). Dynamics of tubulin accumulation during seed germination has been poorly studied so far. Such studies, mostly based on $\beta$-tubulin immunodetection, have shown that tubulin was present in low amount in dry seeds and that it accumulated during seed stratification and germination [8, 46-48]. Yet, microtubule disorganisation following oryzalin treatment does not interfere with seedling germination in Medicago truncatula [49]. Microtubules may not be absolutely required for germination, at least at the early stages. Patterns of cell elongation do not necessarily require microtubules, as shown in meristems [10] and hypocotyls [50]. Furthermore, the absence of microtubules may even weaken the cell wall and speed up cell growth, as shown in shoot meristems [51].

Our results show that CMT reorganisation, which is associated with seed germination, is accompanied by an overexpression of genes coding for $\alpha$-, $\beta$ - and $\gamma$-tubulin, namely TUA6 and TUB3, TUB4, TUB5, TUB6 and 


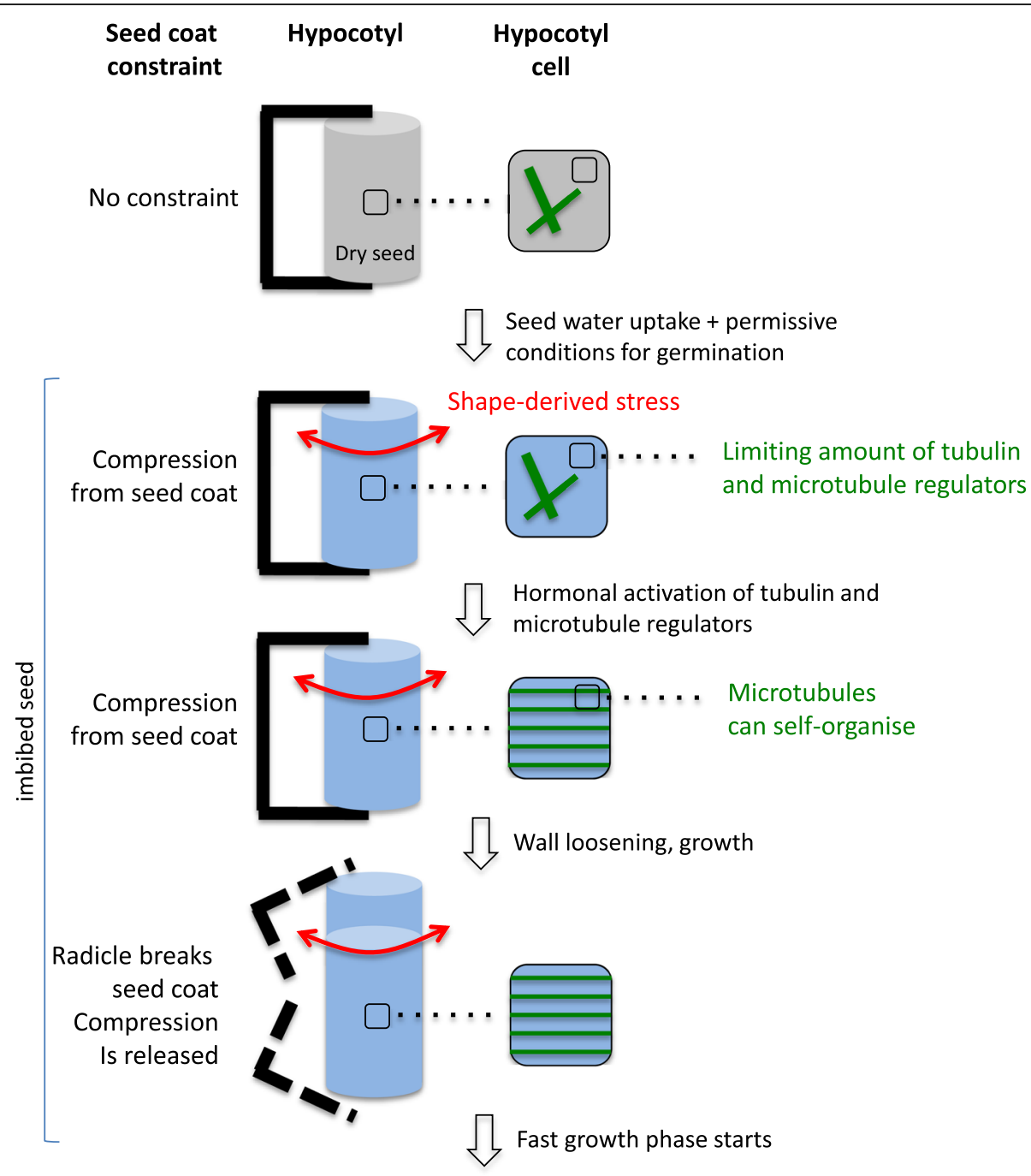

Fig. 6 Model: microtubule self-organisation during seed germination and symmetry breaking in the growing hypocotyl. This model explains how dormancy release allows self-organisation of cortical microtubules when conditions are permissive for germination. See text for explanations

TUBG1 (Figs. 3a-f and 5a-f). Our results echo previously published proteome of seed germination in Arabidopsis [52, 53]. We also show that $\alpha$-tubulin is detectable in dry dormant seeds but that it accumulates dramatically at the onset of radicle protrusion only (Additional file 4: Figure S3). In contrast, EB1a showed the inverse expression pattern since it decreased when seeds germinated (Figs. 3h and 6h). However, there was not a clear cut relationship with radicle elongation and expression of tubulin and EBIa genes since they were not fully repressed or induced by $\mathrm{ABA}$, respectively (Fig. 6a-e, h), which suggests that tubulin accumulation and EB1a may be regulated by other factors than the sole ABA/GA balance. As EB1 overexpression induces the formation of microtubule bundles [54], the relatively high level of EB1 in imbibed dormant seeds might also contribute to explain why CMTs form few thick bundles at that stage. Interestingly, the expression of both CLASP and MOR1 was relatively stable in dormant and non-dormant seeds. As both CLASP and MOR1 also relate to microtubule plus-end tracking proteins like EB1 $[55,56]$, this class of regulators may rather be under post-transcriptional control during germination. The profile of MAP65 proteins matches the dynamics of CMT bundles (Figs. 3f, g and 5f, g). Their expression increased when seeds germinated but was repressed in the presence of ABA. MAP65s are key regulators of cortical CMT organisation because they control CMT bundling [57] thus promoting axial growth of roots and hypocotyl cells in Arabidopsis [20, 58]. Our data therefore strongly suggest that hormones participate in CMT reorganisation through the transcriptional activation of tubulin and CMT regulators. It is worth noting that the analysis of expression of these former genes in ABA- and GA- 
mutant seeds confirmed this finding (Additional file 4: Figure S3). Lastly, the translatome data (Additional file 3: Table S1) provide further molecular insights: translation of protein involved in cell wall remodelling did not occur upon imbibition, but only later on as cells initiated their shape changes. In contrast, the association of transcripts involved in CMT organisation with polysomes occurred at an early time point of imbibition, when seeds were engaged in the germination process, but before detectable cell shape changes.

Our results thus add an additional layer of complexity in the control of growth anisotropy in the hypocotyl during seed germination, along the possible following scenario (Fig. 6): (1) seed water uptake pressurises cells and tissue, but microtubule organisation is first hindered by the limiting amount of tubulin and regulators; (2) release of dormancy and changes in hormonal balance promotes the expression of tubulin and microtubule regulators, thereby allowing their organisation in parallel arrays; (3) shape-derived tensile stress dominates and prescribe transverse CMT orientations, while wall loosening increases stress levels in a feedback loop; and (4) the radicle breaks the envelope.

\section{Conclusion}

We report the dynamic changes in CMT organisation during seed germination. We show that CMTs first appear in Arabidopsis development as few thick bundles, and later on switch to parallel and transverse arrays when the seed germinates, following the predicted tensile stress pattern that is prescribed by tissue pressurisation, compression and cylindrical shape. We also show that the release of dormancy is associated with the expression and translation of a subset of microtubule regulators, thereby triggering the ability of CMTs to organise in organised arrays during germination and to control growth anisotropy. These findings reveal an additional component in the regulation of seed germination by dormancy. As a prospect, taking into account the mechanical constraints applied by the seed coat on the embryo might also shed a new light on the developmental programme behind germination.

\section{Methods}

Plant material, treatments and germination assays Arabidopsis (Arabidopsis thaliana) seeds of the wildtype Col-0 (expression assays, translatome) and of the microtubule-binding domain marker line p35S::GFPMBD [59] in the Wassilewskija Ws-4 background [10] and $\beta$-tubulin marker line p35S::GFP-TUB6 (in Columbia Col-0 background) [60] were used in the experiments. Freshly harvested seeds were dormant and stored at $-20{ }^{\circ} \mathrm{C}$ to preserve their dormancy. Germination assays were carried out by placing 3 replicates of
100 seeds on a single-layer filter paper on the top of cotton wool moistened with deionised water, or with the solutions indicated in the text $\left(10^{-3} \mathrm{M} \mathrm{GA}_{3}\right.$ or $10^{-5} \mathrm{M}$ ABA), in 9-cm Petri dishes at $25^{\circ} \mathrm{C}$ in darkness. Stratification was performed by placing seeds on a filter paper on the top of a cotton wool moistened with deionised water at $4{ }^{\circ} \mathrm{C}$ for 2 or 4 days in the darkness, before their transfer to $25^{\circ} \mathrm{C}$. Germination was evaluated daily, and a seed was considered as germinated when the radicle protruded through the testa.

Because the p35S::GFP-MBD and p35S::GFP-TUB6 constructs used in this study may affect cell physiology, we confirmed that seeds of both lines displayed dormancy [6]: they were unable to germinate at $25^{\circ} \mathrm{C}$ in the darkness, and cold stratification progressively released dormancy (Additional file 1: Figure S1). Four days of stratification were necessary to allow full germination of seeds of both lines at $25^{\circ} \mathrm{C}$ (Additional file 1: Figure S1). The experimental time points used for the experiments in this manuscript were chosen based on these germination curves (arrows on Additional file 1: Figure S1).

\section{Sample preparation and image acquisition by confocal microscopy}

After the various conditions of imbibition mentioned in the text, embryos were extracted from seeds with a forceps under a binocular. Isolated embryos were immediately mounted in a distilled water medium in a glass chamber ( $2 \mathrm{~mm}$ thickness) covered with a coverslip and observed by confocal microscopy.

For Calcofluor staining, isolated embryos were immersed in $0.1 \%(\mathrm{w} / \mathrm{v})$ fluorescent brightener 28 for 30 min at $25^{\circ} \mathrm{C}$ in darkness, and then they were washed $3-$ 4 times with MilliQ water. Stained embryos were mounted in MilliQ water between a glass slide and a coverslip and immediately observed by confocal microscopy using epifluorescent UV irradiation.

Three-dimensional (3D) fluorescence images of hypocotyl cells were acquired on a Leica TCS SP5 confocal microscopy equipped with Hybrid Detectors and Acousto-Optical Tunable Filters/Acousto-Optical BeamSplitters (AOTF/AOBS) for creating spectral emission windows. Argon laser excitation wavelength at $488 \mathrm{~nm}$ and an emission window of 495-580 $\mathrm{nm}$ were used for capturing the GFP signal. The brightener fluorescence signal was measured at an excitation of $405 \mathrm{~nm}$ with an emission window of $412-480 \mathrm{~nm}$. Either a $\times 40$ oil immersion lens (N.A. of 1.25, free working distance of $0.1 \mathrm{~mm}$ ) for GFP images or a $\times 20$ oil immersion lens (N.A. of 0.70 , free working distance of $0.17 \mathrm{~mm}$ ) for images of brightener fluorescence was used.

Confocal z-stacks of embryos at different time points were processed by converting $\mu \mathrm{m}$ (a slice interval in $\mathrm{z}$ step size), which gave a voxel size of $0.152 \mu \mathrm{m} \times$ 
$0.152 \mu \mathrm{m} \times 0.168 \mu \mathrm{m} \quad(x y z)$ and an image size of $155.00 \mu \mathrm{m} \times 155.00 \mu \mathrm{m}(x y)$. Optical slices of 8-bit depth $3 \mathrm{D}$ images were captured using Leica Application SuiteAdvanced Fluorescence (LAS-AF) software.

\section{Visualisation and image analysis}

Confocal z-stacks of embryos were processed by converting $3 \mathrm{D}$ image to a $2 \mathrm{D} x-y$ plane image with maximum intensity projection, and brightness/contrast of images was edited using "Brightness/Contrast" tool in the Image J software. Thirty cells of each embryo (5 embryos for each sample) were used to quantify the anisotropy and average orientation of microtubule with FibrilTool, an ImageJ plug-in, by drawing the region of interest (ROI) in 2D $x-y$ plane images, according to the procedure from [21]. Evaluation of anisotropy was based on the score, with 0 for no order (purely isotropic arrays) and 1 for perfect order. Average orientation of microtubule was the angle with respect to the elongation axis of the cell ( $y$-axis of the image).

The outline of 30 cells in the hypocotyl of each embryo was drawn in optical slices of 3D images, and the mean cell length and width were measured by the ImageJ software.

\section{RNA extraction and qRT-PCR}

A 60-mg aliquot of seeds was ground in liquid nitrogen with insoluble PVP, and total RNA was extracted with a hot phenol procedure according to [61]. Purified RNA $(2 \mu \mathrm{g})$ was reverse transcribed and amplified to synthesise cDNA using the RevertAid Reverse Transcriptase (Thermo Scientific), and quantitative real-time PCR was performed using Mastercycler ep Realplex (Eppendorf). Primer sequences are listed in Additional file 6: Table S2. Relative expression of genes was calculated with the 3 reference genes At5g53560, At4g26410 and At4g34270 as described by [6]. Results presented are the means \pm s.e. of 3 biological replicates.

\section{Immunoblotting}

Seeds (30 mg FW) were ground in liquid nitrogen in 1 $\mathrm{ml}$ of MEB buffer (50 mM Hepes-KOH (pH 7.5), $5 \mathrm{mM}$ EDTA (pH 8.0), 5 mM EGTA (pH 8), 25 mM sodium fluoride, $1 \mathrm{mM}$ sodium orthovanadate, $50 \mathrm{mM} \quad \beta$ glycerophosphate, $75 \mathrm{mM} \mathrm{NaCl}, 20 \%$ glycerol, $0.1 \%$ Triton X-100, $5 \mathrm{mM}$ DTT, $1 \times$ protease inhibitor cocktail). The homogenate was then centrifuged at $14,000 \mathrm{~g}$ for 45 min at $4{ }^{\circ} \mathrm{C}$. Proteins were denaturated in $40 \mu \mathrm{l}$ of Laemmli loading buffer and separated by $10 \%$ sodium dodecyl sulfate-polyacrylamide gel electrophoresis (SDSPAGE). After separation, the proteins were transferred electrophoretically $(20 \mathrm{~V}, 35 \mathrm{~min})$ onto nitrocellulose using a Trans-Blot semi-dry system (BioRad), blocked with $5 \%(\mathrm{w} / \mathrm{v})$ non-fat dry milk and hybridised with $\alpha$ - tubulin antibody (Agrisera, no. AS10680) at 1:5000 dilution in $50 \mathrm{mM}$ Tris, $150 \mathrm{mM} \mathrm{NaCl}, 0.1 \%$ (v/v) Tween 20 and $5 \%(\mathrm{w} / \mathrm{v})$ non-fat dry milk. After washing 3 times with PBS $1 \times$ and $1 \%(\mathrm{w} / \mathrm{v})$ non-fat dry milk, the membranes were incubated with secondary anti-rabbit IgG (Sigma, A6154) at a 1:1000 dilution for $1 \mathrm{~h}$ in PBS $1 \times$ and $1 \%(\mathrm{w} / \mathrm{v})$ non-fat dry milk. Proteins were detected by chemiluminescence (Amersham ECL Prime Western Blotting Detection Reagent).

\section{Statistical analysis}

Significant differences between treatments were determined by analysis of one-way variance (ANOVA) at a significance threshold of $5 \%$ and $1 \%$ using SPSS Statistics software (version 17.0). For comparison of significance between dormant and non-dormant seeds, water and $\mathrm{GA}_{3}$ imbibition on dormant seeds, water and ABA imbibition on non-dormant seeds, statistical analysis was performed using Student's $t$ test $(P<0.05$ and $P<0.01)$. Graphs were created by the SigmaPlot software (version 10.0).

\section{Supplementary information}

Supplementary information accompanies this paper at https://doi.org/10. 1186/s12915-020-00774-8.

Additional file 1: Figure S1. Germination of p35S::GFP-MBD and p355::GFP-TUB6 seeds Germination was performed at $25^{\circ} \mathrm{C}$ in darkness on water $(\mathrm{a}, \mathrm{b})$ or on a solution of gibberellic acid (GA3) or abscisic acid $(A B A)(c)$. DOS, days of stratification. Arrows indicate the time points of microtubule visualization. (PPTX $62 \mathrm{~kb}$ )

Additional file 2: Figure S2. Overview of the experimental model. Overview of the experimental model. A, Anatomy of a whole Arabidopsis embryo extracted from an imbibed seed and stained using calcofluor (scale bar, $20 \mu \mathrm{m}$ ). B, Localisation of cortical microtubules in different areas of Arabidopsis embryo using p35S::GFP-MBD. Embryos were extracted from germinating seeds imbibed for $48 \mathrm{~h}$ at $25^{\circ} \mathrm{C}$ in darkness in the presence of $1 \mathrm{mM} \mathrm{GA}_{3}$ (scale bars, $20 \mu \mathrm{m}$ ). (PPTX $1668 \mathrm{~kb}$ )

Additional file 3: Table S1. Shortlist of microtubule-related genes in the translatome from dormant and non-dormant seeds

Additional file 4: Figure S3. Immunodetection of a tubulin. A 5 Hg aliquot of total protein was loaded on each lane and a-tubulin was detected with a-tubulin antibody in dormant and non-dormant Arabidopsis seeds. $\mathrm{HOI}$, hours of imbibition at $25^{\circ} \mathrm{C}$ in the dark; DOS, days of stratification at $4^{\circ} \mathrm{C}$ in the dark. (PPTX $935 \mathrm{~kb}$ )

Additional file 5: Figure S4. Expression of tubulin and tubulin regulators genes in mutant seeds development. Expression of TUB3, TUB4, TUB5, TUB6, TUA6, MAPD65-1, MAP65-2, CLASP, KTN1, MOR1 and $T B G 1$ in GA and ABA mutant seeds (indicated in figures). Data obtained through the Arabidopsis eFP browser at bar.toronto.ca. (PPTX $11238 \mathrm{~kb}$ )

Additional file 6: Table S2. Primer sequences used for qRT-PCR.

\section{Acknowledgements}

This work was supported by a grant from the China Scholarship Council (CSC) to HY

\section{Authors' contributions}

H.Y. and N.C. performed experiments and analysed data, J.F.G. and S.B. contributed to cellular imaging, evaluation and analysis of the data, O.H. and C. B. designed experiments and wrote the manuscript with input from all coauthors. All authors read and approved the final manuscript. 


\section{Funding}

Imaging Core facility is supported by CNRS, Sorbonne-University and "Region lle-de-France".

\section{Availability of data and materials}

Transcriptome and translatome data analyzed in this article are deposited at the Gene Expression Omnibus (http://www.ncbi.nlm.nih.gov/geo/; accession no. GSE61809) and were previously published by [34]. The raw imaging data supporting the conclusions of this article are available from Figshare (https:// doi.org/10.6084/m9.figshare.12017181) [62].

The material and datasets used and/or analysed during the current study are available from the corresponding author on reasonable request.

\section{Ethics approval and consent to participate}

Not applicable.

\section{Consent for publication}

Not applicable.

\section{Competing interests}

The authors declare no competing interests.

\section{Author details}

${ }^{1}$ Laboratoire de Biologie du Développement, Sorbonne Université, CNRS, F-75005 Paris, France. ${ }^{2}$ Key Laboratory of Pratacultural Science, Beijing Municipality, China Agricultural University, Beijing 100193, China. ${ }^{3}$ Grassland Agri-Husbandry Research Center, College of Grassland Science, Qingdao Agricultural University, Qingdao 266109, China. ${ }^{4}$ Imaging Core Facility, CNRS-FRE3631-Institut de Biologie Paris Seine, Sorbonne Université, F-75005 Paris, France. ${ }^{5}$ Laboratoire de Reproduction et Développement des Plantes, Université de Lyon, ENS de Lyon, UCB Lyon 1, CNRS, INRA, F-69000 Lyon, France.

Received: 10 January 2020 Accepted: 26 March 2020

Published online: 30 April 2020

\section{References}

1. Hashimoto H, Munro E. Dynamic interplay of cell fate, polarity and force generation in ascidian embryos. Curr Opin Genet Dev. 2018;51:67-77.

2. Steinbrecher T, Leubner-Metzger $G$. Tissue and cellular mechanics of seeds. Curr Opin Genet Dev. 2018:51:1-10.

3. Sliwinska E, Bassel GW, Bewley JD. Germination of Arabidopsis thaliana seeds is not completed as a result of elongation of the radicle but of the adjacent transition zone and lower hypocotyl. J Exp Bot. 2009;60(12):358794.

4. Bassel GW, Stamm P, Mosca G, Barbier de Reuille P, Gibbs DJ, Winter R, et al. Mechanical constraints imposed by 3D cellular geometry and arrangement modulate growth patterns in the Arabidopsis embryo. Proc Natl Acad Sci U S A. 2014;111(23):8685-90.

5. Finch-Savage WE, Leubner-Metzger G. Seed dormancy and the control of germination. New Phytol. 2006;171(3):501-23.

6. Leymarie J, Vitkauskaite G, Hoang HH, Gendreau E, Chazoule V, Meimoun P, et al. Role of reactive oxygen species in the regulation of Arabidopsis seed dormancy. Plant Cell Physiol. 2011;53(1):96-106.

7. de Brito CD, Loureiro MB, CAS T, Schuck MR, Fernandez LG, de Castro RD. Behavior of Jatropha curcas L. seeds under osmotic stress: germination and cell cycle activity. Acta Sci Agron. 2015;37(3):279-87.

8. De Castro RD, Zheng X, Bergervoet JHW, De Vos CHR, Bino RJ. Beta-tubulin accumulation and DNA replication in imbibing tomato seeds. Plant Physiol. 1995;109(2):499-504

9. Green PB, King A. A mechanism for the origin of specifically oriented textures in development with special reference to Nitella wall texture. Aust J Biol Sci. 1966;19(3):421-38

10. Hamant $O$, Heisler MG, Jönsson $H$, Krupinski $P$, Uyttewaal $M$, Bokov $P$, et al Developmental patterning by mechanical signals in Arabidopsis. Science. 2008;322(5908):1650-5.

11. Landrein B, Hamant O. How mechanical stress controls microtubule behavior and morphogenesis in plants: history, experiments and revisited theories. Plant J Cell Mol Biol. 2013;75(2):324-38.

12. Creff A, Brocard $L$, Ingram G. A mechanically sensitive cell layer regulates the physical properties of the Arabidopsis seed coat. Nat Commun. 2015;6:6382.
13. Robinson S, Kuhlemeier C. Global compression reorients cortical microtubules in Arabidopsis hypocotyl epidermis and promotes growth. Curr Biol. 2018;28(11):1794-802 e2.

14. Sakiyama M, Shibaoka $\mathrm{H}$. Effects of abscisic acid on the orientation and cold stability of cortical microtubules in epicotyl cells of the dwarf pea. Protoplasma. 1990;157(1):165-71.

15. Sakiyama-Sogo M, Shibaoka H. Gibberellin A3 and abscisic acid cause the reorientation of cortical microtubules in epicotyl cells of the decapitated dwarf pea. Plant Cell Physiol. 1993;34(3):431-7.

16. Lindeboom JJ, Nakamura M, Saltini M, Hibbel A, Walia A, Ketelaar T, et al. CLASP stabilization of plus ends created by severing promotes microtubule creation and reorientation. J Cell Biol. 2019;218(1):190-205.

17. Nakamura M, Lindeboom JJ, Saltini M, Mulder BM, Ehrhardt DW. SPR2 protects minus ends to promote severing and reorientation of plant cortical microtubule arrays. J Cell Biol. 2018;217(3):915-27.

18. Galva C, Kirik V, Lindeboom JJ, Kaloriti D, Rancour DM, Hussey PJ, et al. The microtubule plus-end tracking proteins SPR1 and EB1b interact to maintain polar cell elongation and directional organ growth in Arabidopsis. Plant Cell. 2014;26(11):4409-25.

19. Bouquin T, Mattsson O, Næsted H, Foster R, Mundy J. The Arabidopsis lue1 mutant defines a katanin p60 ortholog involved in hormonal control of microtubule orientation during cell growth. J Cell Sci. 2003;116(5):791-801.

20. Lucas JR, Courtney S, Hassfurder M, Dhingra S, Bryant A, Shaw SL. Microtubule-associated proteins MAP65-1 and MAP65-2 positively regulate axial cell growth in etiolated Arabidopsis hypocotyls. Plant Cell. 2011;23(5): 1889-903.

21. Boudaoud A, Burian A, Borowska-Wykręt D, Uyttewaal M, Wrzalik R, Kwiatkowska D, et al. FibrilTool, an ImageJ plug-in to quantify fibrillar structures in raw microscopy images. Nat Protoc. 2014;9(2):457-63.

22. Verger S, Long Y, Boudaoud A, Hamant O. A tension-adhesion feedback loop in plant epidermis. eLife. 2018;7:e34460.

23. Louveaux M, Rochette S, Beauzamy L, Boudaoud A, Hamant O. The impact of mechanical compression on cortical microtubules in Arabidopsis: a quantitative pipeline. Plant J Cell Mol Biol. 2016;88(2):328-42.

24. Heisler MG, Hamant O, Krupinski P, Uyttewaal M, Ohno C, Jönsson H, et al. Alignment between PIN1 polarity and microtubule orientation in the shoot apical meristem reveals a tight coupling between morphogenesis and auxin transport. PLoS Biol. 2010;8(10):e1000516.

25. Dixit $R$, Cyr $R$. The cortical microtubule array: from dynamics to organization. Plant Cell. 2004;16(10):2546-52.

26. Wasteneys GO, Ambrose JC. Spatial organization of plant cortical microtubules: close encounters of the 2D kind. Trends Cell Biol. 2009;19(2): $62-71$.

27. Elliott A, Shaw SL. Update: plant cortical microtubule arrays. Plant Physiol. 2018;176(1):94-105.

28. Luptovčiak I, Samakovli D, Komis G, Šamaj J. KATANIN 1 is essential for embryogenesis and seed formation in Arabidopsis. Front Plant Sci. 2017:8: 728.

29. Ambrose JC, Shoji T, Kotzer AM, Pighin JA, Wasteneys GO. The Arabidopsis CLASP gene encodes a microtubule-associated protein involved in cell expansion and division. Plant Cell. 2007;19(9):2763-75.

30. Ambrose C, Allard JF, Cytrynbaum EN, Wasteneys GO. A CLASP-modulated cell edge barrier mechanism drives cell-wide cortical microtubule organization in Arabidopsis. Nat Commun. 2011;2:430.

31. Whittington AT, Vugrek O, Wei KJ, Hasenbein NG, Sugimoto K, Rashbrooke $M C$, et al. MOR1 is essential for organizing cortical microtubules in plants. Nature. 2001:411(6837):610-3.

32. Kawamura E, Himmelspach R, Rashbrooke MC, Whittington AT, Gale KR, Collings DA, et al. MICROTUBULE ORGANIZATION 1 regulates structure and function of microtubule arrays during mitosis and cytokinesis in the Arabidopsis root. Plant Physiol. 2006;140(1):102-14.

33. Lansbergen $\mathrm{G}$, Akhmanova A. Microtubule plus end: a hub of cellular activities. Traffic Cph Den. 2006;7(5):499-507.

34. Basbouss-Serhal I, Soubigou-Taconnat L, Bailly C, Leymarie J. Germination potential of dormant and nondormant Arabidopsis seeds is driven by distinct recruitment of messenger RNAs to polysomes. Plant Physiol. 2015; 168(3):1049-65.

35. Yamauchi $Y$, Ogawa M, Kuwahara A, Hanada A, Kamiya Y, Yamaguchi S. Activation of gibberellin biosynthesis and response pathways by low temperature during imbibition of Arabidopsis thaliana seeds. Plant Cell. 2004;16(2):367-78 
36. Steinbrecher T, Leubner-Metzger $\mathrm{G}$. The biomechanics of seed germination. J Exp Bot. 2017;68(4):765-83.

37. Sampathkumar A, Krupinski P, Wightman R, Milani P, Berquand A, Boudaoud $A$, et al. Subcellular and supracellular mechanical stress prescribes cytoskeleton behavior in Arabidopsis cotyledon pavement cells. eLife. 2014; 3:e01967.

38. Ishida K, Katsumi M. Effects of gibberllin and abscisic acid on the cortical microtubule orientation in hypocotyl cells of light-grown cucumber seedlings. Int J Plant Sci. 1992;153(2):155-63.

39. Seung D, Webster MW, Wang R, Andreeva Z, Marc J. Dissecting the mechanism of abscisic acid-induced dynamic microtubule reorientation using live cell imaging. Funct Plant Biol. 2013;40(3):224-36.

40. Da Silva EAA, Toorop PE, Van Lammeren AAM, Hilhorst HWM. ABA inhibits embryo cell expansion and early cell division events during coffee (Coffea arabica 'Rubi') seed germination. Ann Bot. 2008;102(3):425-33.

41. Mirabet $V$, Krupinski $P$, Hamant $O$, Meyerowitz EM, Jönsson H, Boudaoud A. The self-organization of plant microtubules inside the cell volume yields their cortical localization, stable alignment, and sensitivity to external cues. PLoS Comput Biol. 2018;14(2):e1006011.

42. Cosentino Lagomarsino M, Tanase C, Vos JW, Emons AMC, Mulder BM, Dogterom M. Microtubule organization in three-dimensional confined geometries: evaluating the role of elasticity through a combined in vitro and modeling approach. Biophys J. 2007;92(3):1046-57.

43. Islam MS, Kuribayashi-Shigetomi K, AMdR K, Inoue D, Sada K, Kakugo A. Role of confinement in the active self-organization of kinesin-driven microtubules. Sens Actuators B Chem. 2017;247:53-60.

44. Baskin TI. Anisotropic expansion of the plant cell wall. Annu Rev Cell Dev Biol. 2005;21:203-22

45. Stamm P, Topham AT, Mukhtar NK, Jackson MDB, Tomé DFA, Beynon JL, et al. The transcription factor ATHB5 affects GA-mediated plasticity in hypocotyl cell growth during seed germination. Plant Physiol. 2017;173(1): 907-17.

46. Fujikura Y, Dolezel J, Cihalikova J, Bogre L, Heberle-Bors E, Hirt H, et al. Vicia faba germination: synchronized cell growth and localization of nucleolin and alpha-tubulin. Seed Sci Res. 1999;9(4):297-304.

47. Pawłowski TA, Bergervoet JHW, Bino RJ, Groot SPC. Cell cycle activity and Btubulin accumulation during dormancy breaking of Acer platanoides $\mathrm{L}$. seeds. Biol Plant. 2004;48(2):211-8.

48. Cembrowska-Lech D, Kepczynski J. Plant-derived smoke induced activity of amylases, DNA replication and beta-tubulin accumulation before radicle protrusion of dormant Avena fatua L. caryopses. Acta Physiol Plant. 2017; 39(1):39.

49. Gimeno-Gilles C, Lelièvre E, Viau L, Malik-Ghulam M, Ricoult C, Niebel A, et al. ABA-mediated inhibition of germination is related to the inhibition of genes encoding cell-wall biosynthetic and architecture: modifying enzymes and structural proteins in Medicago truncatula embryo axis. Mol Plant. 2009; 2(1):108-19.

50. Peaucelle A, Wightman $\mathrm{R}$, Höfte $H$. The control of growth symmetry breaking in the Arabidopsis hypocotyl. Curr Biol CB. 2015;25(13):1746-52.

51. Sapala A, Runions A, Routier-Kierzkowska A-L, Das Gupta M, Hong L, Hofhuis $H$, et al. Why plants make puzzle cells, and how their shape emerges. eLife. 2018;7:e32794

52. Gallardo K, Job C, Groot SPC, Puype M, Demol H, Vandekerckhove J, et al. Proteomics of Arabidopsis seed germination. A comparative study of wildtype and gibberellin-deficient seeds. Plant Physiol. 2002;129(2):823-37.

53. Galland M, Huguet R, Arc E, Cueff G, Job D, Rajjou L. Dynamic proteomics emphasizes the importance of selective mRNA translation and protein turnover during Arabidopsis seed germination. Mol Cell Proteomics. 2014; 13(1):252-68.

54. Ligon LA, Shelly SS, Tokito M, Holzbaur ELF. The microtubule plus-end proteins EB1 and dynactin have differential effects on microtubule polymerization. Mol Biol Cell. 2003;14(4):1405-17.

55. Grimaldi AD, Maki T, Fitton BP, Roth D, Yampolsky D, Davidson MW, et al. CLASPS are required for proper microtubule localization of end-binding proteins. Dev Cell. 2014;30(3):343-52.

56. Kawamura E, Wasteneys GO. MOR1, the Arabidopsis thaliana homologue of Xenopus MAP215, promotes rapid growth and shrinkage, and suppresses the pausing of microtubules in vivo. J Cell Sci. 2008;121(24):4114-23.

57. Smertenko AP, Chang H-Y, Wagner V, Kaloriti D, Fenyk S, Sonobe S, et al. The Arabidopsis microtubule-associated protein AtMAP65-1: molecular analysis of its microtubule bundling activity. Plant Cell. 2004;16(8):2035-47.
58. Lucas JR, Shaw SL. MAP65-1 and MAP65-2 promote cell proliferation and axial growth in Arabidopsis roots. Plant J. 2012;71(3):454-63.

59. Marc J, Granger CL, Brincat J, Fisher DD, Kao TH, McCubbin AG, et al. A GFPMAP4 reporter gene for visualizing cortical microtubule rearrangements in living epidermal cells. Plant Cell. 1998;10(11):1927-40.

60. Ueda K, Matsuyama T, Hashimoto T. Visualization of microtubules in living cells of transgenicArabidopsis thaliana. Protoplasma. 1999;206(1):201-6.

61. Verwoerd TC, Dekker BM, Hoekema A. A small-scale procedure for the rapid isolation of plant RNAs. Nucleic Acids Res. 1989;17(6):2362.

62. Yan H. Chaumont N, Gilles JF, Bolte S, Hamant O, Bailly C. Materials for "Microtubule self-organisation during seed germination in Arabidopsis". Figshare Datasets 2020. https://doi.org/10.6084/m9.figshare.12017181. Accessed 25 Mar 2020.

\section{Publisher's Note}

Springer Nature remains neutral with regard to jurisdictional claims in published maps and institutional affiliations.
Ready to submit your research? Choose BMC and benefit from:

- fast, convenient online submission

- thorough peer review by experienced researchers in your field

- rapid publication on acceptance

- support for research data, including large and complex data types

- gold Open Access which fosters wider collaboration and increased citations

- maximum visibility for your research: over $100 \mathrm{M}$ website views per year

At BMC, research is always in progress.

Learn more biomedcentral.com/submissions 